\title{
Acerca de las aguas del volcán. Discusiones en torno a los usos y derechos a los recursos hídricos en Nueva España durante las composiciones de $1643^{1}$
}

\author{
About the Volcano Waters. Discussions Regarding the Uses and Rights \\ to Water Resources in New Spain During the Composiciones of 1643
}

\author{
Sergio Eduardo Carrera Quezada \\ Centro de Estudios Históricos, El Colegio de México \\ ID ORCID: https://orcid.org/0000-0003-2047-2390 \\ E-mail: secarrera@colmex.mx
}

Recepción: 19.12.2018

Aprobación: 24.09.2019

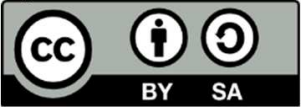

Resumen: El artículo tiene como propósito abordar los derechos a los recursos hídricos y sus concesiones para beneficio de los distintos grupos sociales en la Nueva España. A través de la revisión de las leyes de la época, se discute acerca del dominio, uso común y el usufructo particular del agua. Analizaremos la manera en que se efectuaron los traslados de dominio hacia la propiedad de los vasallos: primero de forma gratuita y, luego, por medio de pagos a la Real Hacienda. Los cambios en los mecanismos de concesión de tierras y aguas se dieron durante la implementación de la regularización agraria realizada a finales del siglo XVI y en las primeras décadas del XVII. Entre las diversas dificultades para instrumentar las regularizaciones, los oidores de la Real Audiencia de México discutieron sobre si la Corona tenía derecho al cobro de otorgamientos de bienes públicos, como originalmente lo eran las aguas. Numerosas adjudicaciones fueron concedidas a españoles con las composiciones colectivas que tuvieron como principal escenario la zona pro ductora de trigo más importante de México en 1643. Los indígenas defendieron sus derechos a la posesión inmemorial de las aguas ante la tramitología de los españoles por legalizar sus propiedades.

Palabras clave: agua, tierras, concesiones, composiciones, Nueva España.

${ }^{1}$ Esta investigación fue desarrollada en el marco del proyecto 6057120004 "La provincia de Metztitlán de la Sierra: estudio del paisaje, poblamiento y apropiación del espacio, siglo XVIII" con financiamiento del Programa para el Desarrollo Profesional Docente (PRODEP). 
Abstract: This paper analyzes the rights to water resources and their concessions for the benefit of different social groups in New Spain. Through a review of the laws of the time, we discuss the domain, common use, and the particular usufruct of water. We will analyze the way in which the transfer of ownership to the property of the vassals was carried out, first free of charge and then by means of payments to the Royal Treasury. Changes in the mechanisms of land and water concession occurred during the implementation of land regularization carried out at the end of the sixteenth century and the first decades of the seventeenth century. Among the various difficulties to implement the regularizations, the oidores of the Real Audiencia de México discussed whether the Crown was entitled to the collection of grants of public goods, as originally the waters were. Numerous adjudications were granted to Spaniards with the collective composiciones that had as main stage the most important wheat producing area of Mexico in 1643. The Indians defended their rights to the immemorial possession of the waters before the procedure of the Spaniards to legalize their properties.

Keywords: water, land, concessions, composiciones, New Spain.

\section{INTRODUCCIÓN}

El estudio acerca del agua compete a los académicos de todos los campos de la ciencia y los historiadores no somos la excepción. La preocupación social y los conflictos por los recursos hídricos han sido una problemática histórica en México y datan, por lo menos, desde el periodo colonial (Taylor, 1975; LipsettRivera, 1992, 1993, 1999; Loreto, 1994; Margadant, 1992). Desde la década de 1970 se ha desarrollado una profusa bibliografía en nuestro país en torno a las relaciones entre los grupos humanos y la naturaleza, en particular sobre los usos sociales del agua ${ }^{2}$.

A la luz de la desbordante producción historiográfica que considera al agua como actor protagónico, nuestro artículo se centra en las concesiones particulares para las actividades agrícolas, ganaderas y productivas que generaban utilidades económicas en la Nueva España. A pesar de que algunos autores han analizado las mercedes y los repartimientos de aguas para beneficio de los regantes (Taylor, 1975; Fernández, Endfield, O’Hara, 2004), las composiciones de las aguas han sido poco analizadas; es decir, los procedimientos jurídicos que corrigieron las irregularidades de aquellos que se aprovechaban de los afluentes sin ningún tipo de título ni licencia o en exceso (Meyer, 1997: 143; Gómez, 2005; Jiménez, 2003). Es, precisamente, durante la ejecución del programa de

\footnotetext{
${ }^{2}$ Actualmente se cuenta con una vastísima bibliografía sobre estudios del agua en México. Con todo, creemos que todavía hace falta un ensayo historiográfico que aborde el conjunto de las investigaciones y temas sobre los recursos hídricos en los distintos periodos históricos. Por esta razón, remitimos a los lectores interesados a los siguientes autores que presentan excelentes balances bibliográficos: Loreto, 2009a; Aboites, 2005, Rojas, 2009; Fernández, Endfield, O’Hara, 2004.
} 
regularización de las propiedades rurales realizado a lo largo de la primera mitad del siglo XVII, cuando se verificó la consolidación de la propiedad de la tierra en la Nueva España. ¿En qué términos se otorgaron el dominio sobre el agua? ¿Las composiciones generaron derechos exclusivos de los recursos hidráulicos, independientemente de la propiedad de la tierra? ¿Cuáles fueron las consecuencias del traslado del dominio de las aguas a favor de los hacendados y labradores que compusieron sus propiedades? ¿Cuántas mercedes y composiciones de agua fueron otorgadas a los solicitantes?

Todas estas cuestiones brotaron en las discusiones entabladas entre los oidores de la Real Audiencia de México y los fiscales de la Real Hacienda encargados de poner en marcha las composiciones de las propiedades agropecuarias en la Nueva España. La principal interrogante era si los recursos hídricos debían considerarse como regalías de la Corona; es decir, de la misma forma que las tierras baldías y como parte de los bienes pertenecientes al Real Patrimonio por los que se debía recaudar una renta correspondiente al derecho de su usufructo. Y es que las reales cédulas decretadas en 1591 que ordenaron las composiciones de tierras irregulares no desvincularon los derechos al agua, pero tampoco los incluyeron explícitamente. En el fondo, el centro del debate de los oficiales virreinales era si la Corona tenía potestad o no para cobrar a los labradores, regantes y molineros por los otorgamientos de acequias, heridos y otros sistemas de aprovechamiento hidráulico, como finalmente se hizo.

Para elaborar este trabajo nos hemos apoyado en las fuentes documentales que se refieren a la composición colectiva de tierras y aguas de los vecinos y labradores españoles de Huejotzingo y Atlixco en 1643. Los oidores resolvieron que el procedimiento en dichas provincias era el método más efectivo para obtener una cobranza inmediata por las propiedades que no contaran con títulos legítimos, supliendo los cuantiosos gastos de las diligencias de mensura y deslinde de los terrenos. Por dicha razón, las copias transcritas de esta composición colectiva aparecen insertas en la mayoría de los expedientes de otras jurisdicciones novohispanas de 1643 y en documentos y títulos posteriores, lo cual indica tanto su importancia legal como su trascendencia histórica para los estudiosos de la propiedad agraria y del aprovechamiento de los recursos hídricos. Pero surge la cuestión: ¿qué tenía de excepcional esta región y qué fue lo que permitió que aquí se lograra la cobranza de composiciones colectivas? Por extraño que parezca, la respuesta está en los volcanes, la conformación de la red hídrica y los servicios ecosistémicos que permitieron una exitosa adaptación de plantas exóticas traídas por los europeos. En consecuencia, la bien lograda 
introducción de nuevos cultivos contribuyó a la transferencia de tierras agrícolas en posesión de indígenas a manos de labradores españoles, muchas de ellas por mecanismos no regulares.

Por último, expondremos cómo las aguas utilizadas para regadío y como fuerza hidráulica perdieron definitivamente su carácter público a partir de las composiciones de 1643, pues fueron incorporadas al patrimonio de la Corona como regalías. El argumento era que el dominio original de las aguas y demás realengos recaía en el monarca, quien gozaba del derecho para concederlas, venderlas o cobrar una renta a los vasallos que se aprovecharan de su utilidad económica. Reservando el derecho común de las aguas destinadas al suministro urbano y al consumo doméstico, el poder virreinal ordenó que los dueños de tierras con riego, de molinos, de ingenios, de batanes y de otras unidades productivas que utilizaran aguas debían obtener su titulación con un pago a las reales cajas. Dicho procedimiento, esto es, las composiciones de las aguas o la adquisición de mercedes con costo para los solicitantes, les otorgó a los beneficiarios el aprovechamiento exclusivo de los recursos hídricos. Inevitablemente, esta exclusividad de derechos acarreó pleitos y disputas por el agua, en los que los pueblos de indios se manifestaron en la defensa de sus derechos inmemoriales.

\section{EL DOMINIO EMINENTE DE LA CORONA Y LOS DERECHOS DE AGUA}

En la Nueva España -y es de suponer que en gran parte de las Indias-, las leyes para el aprovechamiento de las aguas no se desarrollaron de la misma forma que aquellas que regularon la propiedad del suelo, aunque evidentemente eran asuntos que estaban imbricados. Como es bien sabido, el código jurídico que inicialmente impuso la Corona fue el derecho del reino de Castilla, que a la postre venía nutrido de otras jurisprudencias antiguas, como el derecho romano, el Fuero Juzgo de 693, el Fuero Viejo de Castilla de 992, el Fuero Real de España de 1255, las Siete Partidas elaboradas por Alfonso X en 1263, las Ordenanzas Reales de Castilla de 1485 y las Leyes de Toro de 1505 (Lanz, 1982: 23). Estas leyes sustentaban que el dominio original de las aguas correspondía a los príncipes y reyes, quienes lo cedían a las municipalidades en calidad de bienes públicos y comunes para que de forma gratuita se abastecieran las villas, lugares y ciudades (Margadant, 1989: 126). Pero varios tratadistas y jurisconsultos de la época también sostuvieron que desde la Roma antigua existía la propiedad privada del agua de las fuentes, manantiales y pozos que nacieran en los terrenos de particulares, quienes podían explotarlos de manera exclusiva 
siempre y cuando no retuvieran las corrientes y no afectaran a terceros o al común de vecinos y labriegos. De este modo, en el reino de Castilla el dominio del rey sobre los ríos navegables, el uso común sustentado en el res communis ómnium y el derecho de los regantes debían ser preponderantes por encima de cualquier enajenación o apropiación particular del agua (Margadant, 1989: 128-132).

La monarquía hispánica había logrado consumar la conquista de las Indias occidentales e incorporar nuevos territorios a su dominio real, gracias a que las bulas papales recibidas por los Reyes Católicos en 1493 fueron elevadas a la calidad de justos títulos. Después de que los jerarcas mexicas e incas fueron despojados de su autoridad y gobierno, la Corona se adjudicó el dominio eminente en todos los territorios sojuzgados, imponiendo sus instituciones políticas y el beneficio privativo sobre las riquezas minerales, las salinas, el comercio de tintes y otros estancos que pasaron a la administración directa de la Real Hacienda. Las tierras, las aguas superficiales y los bosques fueron incorporados al Patrimonio Regio como bienes baldíos y públicos, con excepción de aquellos espacios y recursos que eran propios, asignados o reconocidos para las poblaciones y los que pertenecían a caciques indígenas. Así, la Corona se apropió de todos los baldíos, bosques y aguas en forma de regalías y sólo podían ser concedidos a un particular o corporación mediante las instancias autorizadas por el monarca. Dicha concesión, conocida como merced o gracia real, era el título legal que transfería los derechos de la Corona a la persona o corporación que lo había solicitado por las vías jurídicas a las instancias competentes (Ots Capdequí, 1989: 34; Peset, Menegus, 1994: 568).

Con el traslado de las leyes castellanas y la incorporación de ciertas costumbres indígenas se creó el derecho indiano, que fue un conjunto de normas de aplicación casuística y flexible dependiendo de las circunstancias de cada lugar en América. Conviene recordar que antes de la publicación de la Recopilación de Leyes de Indias en 1680 no hubo un cuerpo jurídico uniforme dirigido para el gobierno de las audiencias americanas. Por lo tanto, en ambos virreinatos tuvieron vigencia las Siete Partidas que sostenían la potestad del monarca, pero también la Ius Commune que reconocía el derecho de los vecinos representados por los cabildos de las ciudades, villas españolas y repúblicas de naturales (Meyer, 1997: 126). La consideración a las costumbres de los naturales se observa en una real cédula de 1536 que mandó tomar en cuenta la forma en que dividían sus tierras y repartían las aguas, para que los españoles siguieran y reconocieran ese mecanismo (León Pinelo, 1992 [1680]: 2106). 
En los años inmediatos a la conquista se pensaba que el agua era un recurso abundante y que podía utilizarse tanto para consumo humano como para actividades productivas. Las primeras leyes para regular el acceso a las aguas estaban imbricadas en la cuestión agraria y, al mismo tiempo, se mezclaban con otras sobre el aprovechamiento de los montes, pastos y demás bienes mostrencos. Por ejemplo, la real cédula decretada por Carlos V el 20 de abril de 1533 ordenó que los pastos, montes y aguas contenidos en los sitios otorgados a los españoles mediante mercedes debían ser comunes (León Pinelo, 1992 [1680]: 2106). Inclusive, la ordenanza del virrey Antonio de Mendoza de 1536 (Lanz, 1982: 185-191) y las ordenanzas del marqués de Falces de 1567 (Solano, 1984: 32, 205-208) fueron disposiciones importantes que establecieron las primeras unidades de medición en Nueva España, pero no dejaron de manifestar la posición superlativa del dominio y usufructo de la tierra por encima de los recursos hídricos.

Ante el carácter fluctuante de los derechos al agua, existe el debate entre los especialistas referente a si el traslado de dominio y la propiedad al agua estaban implícitos en las mercedes otorgadas para beneficiar tierras de labor agrícola. Michael Meyer (1997: 132) señala que en gran parte de las tierras concedidas no se encuentra explícito el derecho de adjudicación de agua; incluso, cuando en ellas se mencionó cierto privilegio, no necesariamente indicaba que haya sido en propiedad plena. Sin embargo, este autor advierte que el asunto debe observarse en el tipo de tierras concedidas, a saber: de pan sembrar -para cultivo de trigo sin riego-, de pan coger -temporal o lluvias- y de pan llevar para cultivos que precisan de riego-, por lo que colige que únicamente estas últimas incluían el dominio implícito de los recursos hídricos. Al respecto, Guillermo Margadant (1989: 141-142) alude a un sinnúmero de situaciones derivadas de una desordenada entrega de mercedes, pues encuentra que los títulos que sólo concedían agua eran dados porque había una merced de tierras anterior que por algún motivo no registró el derecho a la irrigación. En unos casos la merced de agua era entregada para aumentar el volumen y en otros para prever necesidades de suministro en el futuro. Por nuestra parte, hemos encontrado en las citadas ordenanzas del marqués de Falces de 1567 que las caballerías de tierra dadas por mercedes debían medir 609,458 varas cuadradas $-42,8$ hectáreasy estar suministradas con dos surcos de agua $-6,48$ litros por segundo- para sembrar diez fanegas de trigo o cuatro surcos de agua -12,96 litros por segundopara sembrar caña de azúcar, mientras que un molino o batán debía estar dotado 
de tres surcos de agua -9,72 litros por segundo- ${ }^{3}$ (Solano, 1984: 206). Quedaba sobreentendido, entonces, que el solicitante de este tipo de mercedes tenía derecho tácito a dichas cantidades de agua.

Con todo, los especialistas coinciden en que la Corona también concedió mercedes de aguas para particulares, corporaciones y pueblos de indios, aunque no queda claro si dichos títulos permitían la apropiación exclusiva de los recursos hídricos. Para Meyer (1997: 143), las mercedes de agua fueron entregadas únicamente en su condición de realengos; es decir, si se comprobaba que su origen perene se hallaba en tierras que no tuvieran titulación previa y que no perjudicaran a terceros o al bien público. Castañeda (2005: 71) afirma que la propiedad privada del agua no existía de la misma forma que la de la tierra, toda vez que las mercedes de agua otorgaban el dominio útil; es decir, sólo el usufructo mas no la propiedad absoluta. Margadant (1989: 143), en cambio, sugiere que los derechos al agua transferidos por medio de mercedes eran más precarios que los de la tierra, porque un solicitante de este tipo de título estaba sujeto a una "flexible distribución equitativa" para garantizar el beneficio general y colectivo antes que el provecho individual. Más adelante expondremos nuestra opinión al respecto, a partir de la evaluación cuantitativa y cronológica de las mercedes de aguas.

Al margen de la mención explícita de agua en la concesión de tierras, los repartimientos eran procedimientos judiciales emprendidos por los cabildos cada vez que se presentaban desacuerdos entre los regantes por el uso de los ríos, acequias, remanentes y sobrantes. Gloria Camacho $(1998 ; 2010)$ apunta que los repartimientos verificaban los derechos previos de los poseedores originarios, pero también otorgaban nuevos derechos a otros beneficiarios. Cuando los acuerdos no eran respetados por algún beneficiario, los agraviados podían solicitar la intervención de las autoridades locales para realizar un nuevo repartimiento, buscando que se les reconocieran sus antiguos derechos. La autora afirma que la práctica de los repartimientos coadyuvó a la apropiación privada del agua por parte de los dueños de tierras particulares y molinos.

Conviene llamar la atención acerca de los asuntos metodológicos y la documentación sobre concesiones de mercedes de agua. William Taylor (1975) abordó los primeros 31 volúmenes del grupo documental Mercedes del Archivo General de la Nación de México. En su estudio analizó cerca de 4000 mercedes de tierra para toda la Nueva España entre 1542 y 1616, de los cuales dijo que un

\footnotetext{
${ }^{3}$ En el sistema métrico decimal un surco de agua equivale a 3,41 litros por segundo o 194,4 litros por minuto. Sobre la conversión de medidas hidráulicas y su equivalencia moderna, consultar Palerm Viqueira, Chairez Araiza (2002) y Salazar (2000: 39).
} 
centenar correspondía a concesiones de agua, especialmente para uso doméstico. Además de las investigaciones regionales que aportan información cuantitativa sobre mercedes de agua en jurisdicciones específicas, como en Tehuacán (Salazar, 2000) y en Oaxaca (Fernández, Endfield, O’Hara, 2004), considero que el pionero trabajo de Taylor es el único que ofrece una perspectiva amplia y general de las concesiones de agua en términos cuantitativos, al menos hasta la primera mitad del siglo XVII.

Cuatro décadas después del artículo de Taylor, nosotros hemos hecho una nueva exploración en las bases de datos del fondo Mercedes. El resultado arrojó un total de 713 expedientes que contenían la palabra "agua", desde el año 1542 hasta 1799. Con la reserva de considerar que las descripciones de los registros pueden presentar numerosas erratas, este primer acercamiento ayuda a clasificar la diversidad de categorías de documentos, pues no solamente se refieren a concesiones por mercedes, sino también a mandamientos acordados, composiciones, contradicciones, amparos, arrendamientos, conciertos, repartimientos y conducción de aguas, entre otros procedimientos jurídicos. En el Anexo 1 descargamos, concentramos y sistematizamos toda esta información. Las tablas aportan datos sobre el tipo de beneficiarios o actores involucrados, a saber: españoles, clero, pueblos de indios y vecinos de ciudades o villas. La organización cronológica contribuye a observar el paulatino incremento de expedientes sobre los recursos hídricos, cuya mayor concentración se dio durante la primera mitad del siglo XVII, con un total de 315 registros, de los cuales 242 corresponden a españoles, 32 al clero, 26 a vecinos de diversas provincias, 12 a pueblos de indios y 3 sin especificar. En el siguiente periodo, de 1651 a 1700, se nota una disminución en la cantidad de expedientes -121 en total- y también en el número de categorías, ya que no hay datos de "Composiciones de tierras y caballerías", "Donaciones", "Solares" ni "Conciertos". Entre 1701 y 1750 se contabilizaron 135 expedientes, pero aparecen de nuevo las categorías antes mencionadas, además de "Conducción", "Conexión", "Medida" y "Venta" de aguas. Para el último periodo, de 1751 a 1800, se aprecia una disminución notable de la mitad de registros con únicamente 65 expedientes. La siguiente gráfica ayuda a visualizar el contenido del Anexo 1. 
GRÁFICA 1. NÚMERO DE EXPEDIENTES CONCERNIENTES A RECURSOS HÍDRICOS EN EL GRUPO DOCUMENTAL MERCEDES, POR TIPO DE BENEFICIARIO O ACTORES INVOLUCRADOS (1542-1799)

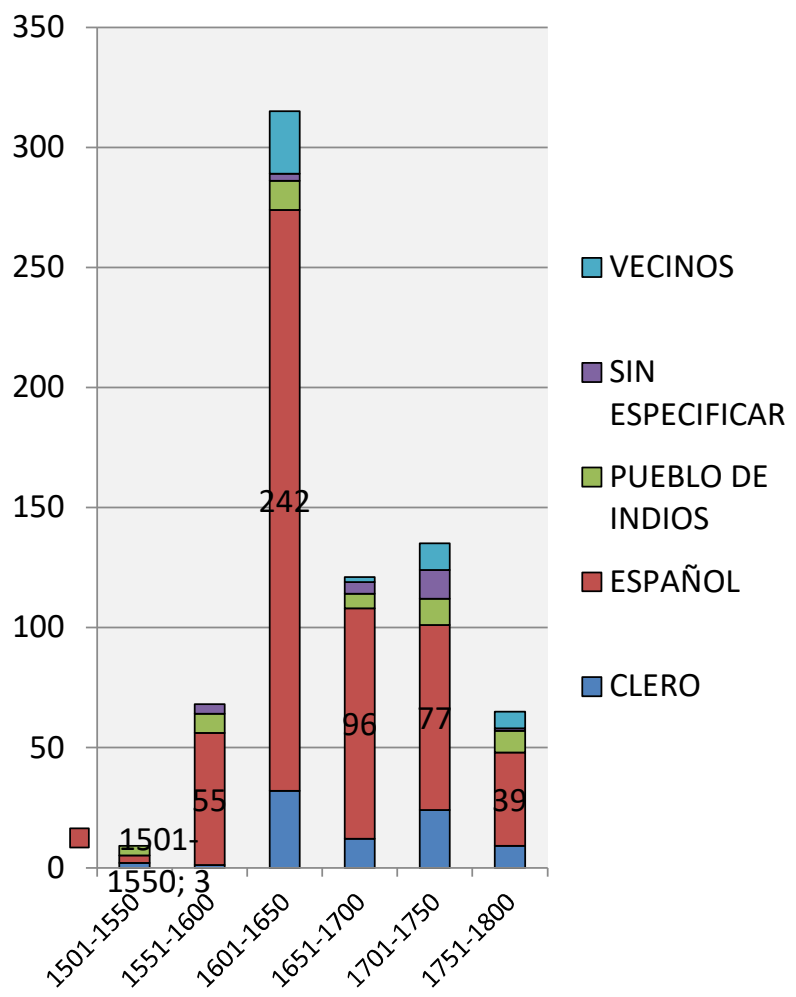

Fuente: elaboración propia.

Debemos ser muy enfáticos en que el ejercicio cuantitativo realizado en el grupo documental de Mercedes es apenas un acercamiento al universo de la documentación referida sobre el tema del agua durante el periodo virreinal. Es un primer paso que sirve de invitación a una investigación de mayor profundidad cualitativa de los expedientes de este y otros acervos, que además considere las condiciones geográficas y ambientales propias de cada ecosistema donde se registraron concesiones de derechos de aguas. Este análisis queda pendiente por realizar. Por ahora podemos sugerir que estas fuentes documentales reflejan las prácticas jurídicas de las autoridades virreinales para regular los derechos de los recursos hídricos, pero sobre todo expresan los intereses, los acuerdos y las negociaciones de los grupos sociales por el manejo, la competencia y el control de estos recursos. En este sentido, deben de leerse entre líneas las ideas que en aquella época tenían los actores sociales con respecto a la naturaleza y sus elementos. 


\section{INICIOS DE LA REGULARIZACIÓN AGRARIA}

Con el propósito de remediar las ocupaciones ilícitas y de corregir la desordenada entrega de mercedes despachadas por los cabildos y presidentes de las audiencias en las Indias, el primero de noviembre de 1591 fueron decretadas las reales cédulas que reformaron los mecanismos para la concesión de títulos de tierras de realengo. Así, el rey Felipe II dio inicio a un programa de regularización agraria que tuvo como argumento ejercer su derecho a las regalías para beneficio de la Real Hacienda, so pretexto de cubrir los gastos de guerra y marina, pero cuyo objetivo principal fue retirar la gratuidad para la concesión de nuevas mercedes. A partir de entonces las tierras baldías debían ser adquiridas en subasta pública, mientras que a los poseedores de tierras se les brindó la oportunidad de reparar su situación irregular y obtener la titularidad mediante la vía jurídica de la composición; es decir, por un desembolso a favor de las cajas reales. A diferencia de las mercedes, las composiciones no fueron títulos originarios de la propiedad, sino procedimientos legales que conferían la indulgencia del monarca, siempre y cuando se verificara el pago monetario ajustado entre la autoridad competente y la persona beneficiada (Torales, 2005: 40-41; Carrera, 2018: 139).

En las reales órdenes arriba citadas se reservaron los bienes públicos de las ciudades y poblaciones, así como los repartimientos de tierras para sementeras y crianzas confirmados a los pueblos de indios congregados. Pero en relación al dominio de aguas no hacen ninguna mención, por lo que debió entenderse que el proyecto de reforma agraria iba dirigido a las tierras productivas en posesión de particulares: estancias, chácaras, cortijos y caballerías. No obstante, dichas leyes ordenaron que después de reservar los bienes de consejos y de los indígenas, "todas las demás [tierras] las podáis dar y conceder de nuevo por tierras, estancias, chácaras y heridos de molino, a quien los quisiere y pidiere, mediante la dicha composición, regulándola conforme a lo que se les pidiere" (Solano, 1984: 275). A la luz de lo anterior, solamente la infraestructura hidráulica y el agua utilizada como fuerza motriz para los molinos entraban en los recursos que podían ser solicitados a través de merced, específicamente por medio del pago de composición. Incluso, lo que dicha ley explicita es la composición de los heridos, es decir, de las aperturas de canales para la conducción del agua de un río, mas no el líquido en sí mismo.

A los virreyes se les encomendó la difícil tarea de conducir las diligencias y visitas a las provincias para verificar la posesión legal de cada una de las pro- 
piedades agropecuarias particulares. Sin embargo, en la Nueva España el virrey Luis de Velasco retrasó el cumplimiento de las reales cédulas que ordenaron las composiciones y venta de baldíos, pues argumentó ante el monarca que los labriegos y ganaderos españoles no tenían la capacidad económica para soportar dicho gravamen y propuso que las composiciones debían corresponder únicamente a quienes las quisieran realizar de manera voluntaria, sin obligarlos a manifestar sus títulos. Aunque se lograron efectuar algunas cobranzas por composiciones, lo cierto es que, hasta el final de su gobierno, Velasco continuó otorgando mercedes de forma gratuita. Le correspondió al siguiente virrey, Gaspar de Zúñiga y Acevedo, afrontar las exigencias de la Corona para ejercer la cobranza de las regalías, de modo que el 9 de marzo de 1601 decretó una ordenanza que impuso el cobro a cada merced solicitada, el cual era tasado por el valor de la cuarta parte del sitio demandado. Desde entonces, las mercedes para los españoles dejaron de ser gratuitas (Carrera, 2018: 145).

\section{LOS PRIMEROS ENSAYOS DE COMPOSICIONES}

En la primera década del siglo XVII las mercedes ya tenían un costo por su entrega, pero aún no se implementaban las subastas de baldíos ni las diligencias de composiciones en las provincias novohispanas, como manifestó el virrey Juan de Mendoza y Luna en una carta al rey en 1605. Durante los reinados de Felipe III y Felipe IV se emitieron nuevas órdenes en 1618 y 1624 que reiteraron las urgencias financieras de la Real Hacienda y la necesidad del cobro inmediato de las regalías (Carrera, 2018: 146, 148).

La real cédula decretada el 27 de mayo de 1631 tuvo importantes repercusiones en la Nueva España, pues obligó al virrey Rodrigo Pacheco de Osorio a delegar al oidor de la Audiencia Juan González Peñafiel para comenzar las diligencias de composiciones en la provincia de Izúcar. Esta jurisdicción se encontraba cerca de la ciudad de Puebla y contaba con numerosas propiedades agrícolas que tenían una elevada producción de trigo y caña de azúcar, además de molinos, ingenios y trapiches que procesaban dichos cultivos. Al concluir su inspección, González Peñafiel tasó la composición de las tierras de todos los vecinos en 90.000 pesos, elevada suma que lógicamente se negaron a liquidar. Además, el oidor reconoció que los labradores españoles "tenían usurpadas algunas datas de agua". Los labriegos enviaron su apelación a la Real Audiencia y de ahí fue enviada al Consejo de Indias para esperar una resolución (Torales, 2005: 54). 
Mediante la real cédula de 4 de mayo de 1635 que ordenó la recaudación de fondos para la Armada de Barlovento, el gobierno novohispano intentó dar seguimiento a los procedimientos de composiciones. El virrey Rodrigo Pacheco de Osorio ordenó a Juan Guillén Valles efectuar las diligencias en la provincia de Chalco, otra zona agrícola muy productiva y más cercana a la ciudad de México. Aunque no recibió instrucciones específicas, el licenciado Guillén debía efectuar lo mismo que en Izúcar: recorrer toda la jurisdicción para verificar la legalidad de los títulos y las dimensiones de todas las propiedades rurales, pero esta vez acompañado de un escribano, un intérprete y dos agrimensores. Pero luego que notificó el motivo de las diligencias -el cual tenía un objetivo fundamentalmente recaudatorio- recibió una contundente oposición por parte de los labradores y vecinos. Adujeron que el costo de las diligencias y los salarios de la comitiva iban a resultarles más costosos que lo que valían sus tierras, de modo que ofrecieron un pago inmediato de 4.280 pesos en un primer plazo por la composición de sus 52 propiedades agrícolas (Carrera, 2018: 149).

A partir de estas primeras experiencias de composiciones de tierras, el marqués de Cadereyta informó el 17 de abril de 1636 al Consejo de Indias que la cobranza de esta regalía iba por buen camino. No obstante, la realidad era que el gobierno virreinal había pactado con los vecinos de estas provincias para suspender las mediciones de terrenos y revisiones de títulos a cambio de pagos por composiciones colectivas a plazos. Por ejemplo, el asunto en la provincia de Izúcar no se resolvió sino hasta 1643, durante el gobierno del virrey García Sarmiento de Sotomayor, conde de Salvatierra, a quien le correspondió negociar con los vecinos el pago de la composición establecida en 66.000 pesos divididos en tres plazos, monto que tampoco fue saldado por completo (Torales, 2005: 54).

Pronto los vecinos de las provincias cercanas percibieron la impaciencia del gobierno novohispano por cumplir con las órdenes de la Corona y aprovecharon la oportunidad de obtener títulos de composiciones sin la necesidad de practicar las diligencias. Como veremos a continuación, las composiciones colectivas en el valle de Atlixco y la cuenca del río Atoyac fueron paradigmáticas, porque finalmente el conde de Salvatierra resolvió que su procedimiento debía tomarse como modelo para aplicarlo a las demás provincias de la Nueva España. En 1643, Gabriel Alvarado, vecino y labrador de la provincia de Huejotzingo, estuvo a cargo del trámite de composición de haciendas, molinos, aguas, ventas, mesones y casas de todos los vecinos y labradores de dicha jurisdicción, cuyo costo fue de 16.000 pesos (BNM, Tenencia de la Tierra, caja 4, exp. 250, 55 ff.) Cabe anotar que, a partir de esta composición, el asunto del dominio de las aguas 
adquirió relevancia pues, por un lado, los regantes y dueños de molinos buscaron obtener derechos de concesión mediante esta vía jurídica y, por el otro, los oidores y fiscales de la Real Audiencia no estaban seguros si podían efectuar estas adjudicaciones como si se tratase de una regalía más de la Corona.

\section{El VALLE DE ATLIXCO EN LOS ALBORES DEL SIGLO XVII}

Debido a que las composiciones en el Valle de Atlixco fueron el modelo que se aplicó en el resto de las provincias y jurisdicciones de la Nueva España entre 1643 y 1645, es obligado preguntarse qué fue lo que llevó al gobierno virreinal a tomar esta decisión. La respuesta debemos encontrarla en la historia ambiental; es decir, en cómo las características ecológicas y la extensa red hídrica provista por la Sierra Nevada fueron favorables para la agricultura de plantas exóticas y la crianza de especies animales traídas por los europeos, lo que propició un rápido crecimiento de la propiedad española (Garavaglia, 1996).

El sistema volcánico transversal -cuyas principales elevaciones son los volcanes Popocatépetl con 5.472 msnm e Iztaccíhuatl con 5.386 msnm (Macías, 2005)- es el principal regulador de los ecosistemas en el Alto Atoyac y en el Valle de Atlixco. Las reservas de nieve y el deshielo dan origen a numerosos escurrimientos que, junto al nacimiento de manantiales y a la recarga temporal de lluvias, conforman la extensa red hídrica de las cuencas de los ríos Atoyac y Nexapa. Las aguas superficiales de esta red hídrica, el clima templado y la calidad de los suelos aluviales han provisto de servicios ecosistémicos a los grupos humanos por lo menos 6.000 años atrás (Mapa 1). La cubierta vegetal en las faldas de los volcanes proporcionó diversos recursos forestales, mientras que los terrenos llanos de la planicie poblana fueron transformados en extensos campos de cultivo. Las tierras de irrigación han sido aprovechadas por los indígenas muchos siglos antes de la invasión europea para cultivar maíz, calabaza, chile, frijol, tomate, amaranto y algodón, entre otras plantas nativas. Con la llegada de los españoles se introdujo en la zona templada el cultivo del trigo, de la vid, de árboles frutales y de moreras para la cría de gusanos de seda. Las condiciones climáticas y la calidad del suelo en la vertiente sur y cálida del valle fueron óptimas para la adaptación de la caña de azúcar (Garavaglia, 1996: 100).

Pero no sólo los ecosistemas y la exitosa adaptación de los nuevos cultivos redundaron en la configuración de las estructuras agrarias y cambios en el paisaje. El debilitamiento de la nobleza indígena, la crisis demográfica y la imposición de un sistema económico que exigió nuevas cargas tributarias fueron 
factores que incidieron en la transferencia de suelos agrícolas a manos de españoles desde épocas muy tempranas. Por ejemplo, en 1532 las autoridades indígenas de Huejotzingo y Calpan autorizaron el reparto de tierras a colonos en espacios que parecían estar vacíos, pero que en 1539 fueron reclamados por los nobles de Cholula. Más tarde, en 1534 y 1551, los españoles arrendaron tierras de cultivo en los márgenes del río Cantarranas, que después adquirieron mediante contratos de compra a los indígenas. Con la fundación de la Villa de Carrión en 1579 - actualmente Atlixco-, también se vendieron algunas tierras a favor de hispanos. Además, el programa de congregaciones efectuado a finales del siglo XVI y comienzos del XVII en los pueblos del valle -Acapetlahuacán, Aguacomulican, Huequechula, Coatepec, Huiluco, entre otros-, propició el abandono de muchas sementeras, que a la postre fueron solicitadas por los labradores ibéricos mediante la vía de las mercedes (Prem, 1988: 146; Paredes, 1991: 67; Garavaglia, 1996: 98).

Mapa 1. Provincias de Atlixco y Huejotzingo, 1643

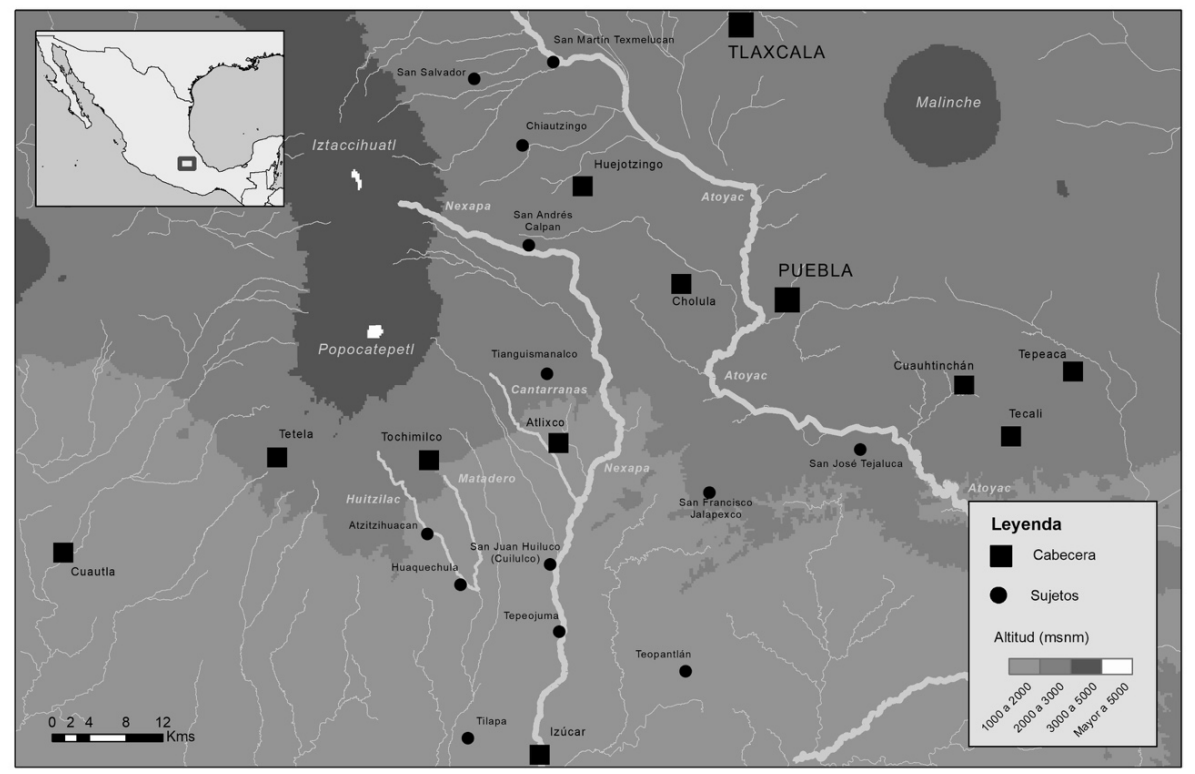

Fuente: Prem, 1988: 146; Garavaglia, 1996: 98.

Así, el origen de la propiedad española comenzó en la zona septentrional del Valle y se fue extendiendo a lo largo de las corrientes de los ríos de Atoyac, Nexapa, Cantarranas y Huitzilac hasta llegar a la zona cálida en Izúcar. Hacia la 
primera mitad del siglo XVII, esta vasta zona habría sido profundamente transformada, pues el cultivo de maíz fue paulatinamente desplazado por la producción de trigo y lo mismo ocurrió con las plantaciones de algodón por las de caña de azúcar. La configuración agraria también produjo nuevas relaciones sociales y laborales entre propietarios españoles y trabajadores indios. En 1638 el marqués de Cadereyta informó a su majestad que las epidemias se habían cobrado la vida de 40.000 naturales y que dicha disminución de la mano de obra afectó la producción de trigo e influyó en el aumento de su precio. A pesar de ello, para esas fechas el Valle de Atlixco y toda la región denominada Puebla-Tlaxcala era donde se producía la harina de trigo que era enviada a la ciudad de México, Puebla y el Caribe (Zavala, 1994: 19; Loreto, 2009b).

\section{LOS REPARTIMIENTOS DE AGUA}

El problema de la distribución de tierra para los españoles en el Valle de Atlixco causó discusiones acerca del uso y disfrute de las acequias o apantles, presas y tomas de agua para irrigar sus terrenos de trigo y plantaciones de caña, en detrimento de las sementeras de los pueblos de indios. Los indígenas alegaron que en la última década del siglo XVI había aumentado el número de labradores de origen europeo, quienes atajaban los afluentes de los ríos para conducir agua hacia sus propiedades, sirviéndose no sólo de las obras hidráulicas prehispánicas, sino también de la apertura de nuevos canales y acequias, lo que causaba la disminución del caudal natural de las corrientes. Esta situación, así como las disputas entre los pueblos de indios, orilló a las autoridades virreinales a regular la distribución del agua por medio de repartimientos; es decir, de derechos a tandas de agua por días. Las aguas del río Huitzilac fueron de las primeras en ser repartidas por autoridades españolas: en 1538 por el corregidor Hernando de Helguera para el beneficio de los pueblos de Tochimilco, Huilango, Atzitzihuacan y Huequechula; y en 1550 por mandamiento del virrey Antonio de Mendoza (Garavaglia, 1996: 109). Después siguieron los repartimientos del río Nexapa, en 1560 por Luis Segri, alcalde mayor de Izúcar, y luego en 1571 por Juan de Hierro, corregidor de Huejotzingo. La corriente del Atoyac y sus afluentes fueron repartidas por orden del virrey Luis de Velasco en 1592 (Camacho, 1998).

Estos repartimientos no solucionaron por completo los conflictos por el uso de las corrientes de los ríos que surcaban el valle, pues los beneficiarios localizados río abajo continuamente se quejaron que sus derechos se venían afectados por los regantes de río arriba. El aumento en el número de labradores, el creci- 
miento de las propiedades rurales y la fundación de molinos contribuyeron a que la competencia por los recursos hídricos se intensificara. Las reclamaciones trascendieron el ámbito local y llegaron a instancias más elevadas, por lo que el gobierno virreinal se vio obligado a ordenar nuevos repartimientos de agua durante las primeras décadas del siglo XVII. El primero fue efectuado en 1605 en la acequia de Cuilulco, ubicada en la corriente del río Nexapa que conducía su afluente a los productores de trigo en el sur de Atlixco y al pueblo de San Juan Huiluco. Entre 1608 y 1611 hubo otros interesados por la distribución del agua en esta acequia, como el escribano público del cabildo de la Villa de Carrión, Jerónimo de Salazar, dueño de una hacienda que había hecho la repartición de la misma acequia a petición de los indios del pueblo de San Juan Huiluco. Este repartimiento permitió a los hacendados de río arriba la captación de agua en jagüeyes, situación que provocó el descontento de los naturales de Izúcar, pues argumentaron que los remanentes no les eran suficientes para el riego de sus sementeras. En 1622, las autoridades indígenas de Izúcar exigieron un nuevo repartimiento en la corriente inferior del río Nexapa, el cual fue concedido por el virrey Diego Carrillo de Mendoza y Pimentel, marqués de Gelves. En 1635 se practicó otro repartimiento de la corriente del mismo río, desde la acequia de Cuilulco hasta el pueblo de Izúcar, cuya distribución fue por medio de unidades de medida de agua asignadas a cada regante (Camacho, 2010: 292, 302).

Los repartimientos de agua efectuados en las primeras décadas del siglo XVII ratificaron los derechos inmemoriales de los pueblos en el uso de las acequias, pero al mismo tiempo confirmaron nuevos derechos para los labradores recién llegados al valle. Los problemas por la distribución del agua se incrementaron conforme se fundaron nuevas tierras de labor y molinos, de modo que los repartimientos se hicieron cada vez más frecuentes a petición de los demandantes afectados, que por lo general eran los indígenas de los pueblos o los españoles cuyas mercedes no estipulaban el usufructo explícito del agua. Sirve de ejemplo el repartimiento de 1622, cuando los dueños de las haciendas y los indígenas de Izúcar alegaron poseer, respectivamente, mercedes y repartimientos de agua concedidos por los virreyes. El repartimiento de agua que se efectuó entre los labradores en 1635 tuvo resonancia en la composición colectiva de 1643, porque en dicho procedimiento los beneficiados pretendieron demostrar su propiedad sobre acequias y jagüeyes (Camacho, 1998: 152-153, 189-193). 


\section{EL AGUA EN LAS COMPOSICIONES COLECTIVAS}

Como mencionamos anteriormente, Gabriel Alvarado fue el representante legal que estuvo a cargo de la composición colectiva de los labradores de las jurisdicciones de Huejotzingo y Atlixco. Su solicitud fue revisada en la Audiencia de México por el licenciado don Luis de Berrio y Montalvo, alcalde de la Sala del Crimen, y por don Francisco Manrique de Lara, fiscal de la Real Hacienda. En su escrito de presentación, Gabriel de Alvarado ofreció el pago de 16.000 pesos para que los oidores admitieran la composición colectiva de los vecinos, siempre y cuando se respetara el acuerdo de suspender el envío de jueces y agrimensores a su provincia; también indicó que, durante el gobierno del marqués de Cadereyta, los vecinos ya habían ofrecido el pago de 10.000 pesos, pero ciertas dificultades lo impidieron liquidar. El alcalde Berrio y Montalvo aceptó la contribución prometida por Alvarado, aunque el fiscal Francisco Manrique, si bien no se oponía al pago de composición, planteó una serie de problemas de orden jurídico que se estaban presentando en estos procedimientos de composiciones colectivas.

En el primero de ellos, el fiscal expuso que los vecinos de la Villa de Carrión habían dado un memorial para tramitar sus composiciones por el precio de 20.000 pesos, pero desconocía cuáles eran las cédulas, instrucciones y capítulos de cartas que se citaban en dicho memorial, de modo que le despertó suspicacias. Tampoco sabía el número de haciendas ni la calidad de las tierras de cultivo que comprendía la jurisdicción de Atlixco, porque sin la práctica de las diligencias era imposible conocer las superficies reservadas en legítima propiedad de aquellas que eran realengos y poseían en demasía, así que cualquier ofrecimiento era una subestimación del valor real de las propiedades en detrimento del Real Patrimonio. También advirtió que la composición de las propiedades de eclesiásticos y monasterios era contra derecho por estar estipulada la prohibición impuesta a los beneficiarios de mercedes de traspasar sus tierras a los religiosos, situación que en ese momento estaba discutiéndose en el Consejo Real de las Indias.

Sin embargo, el punto que verdaderamente tuvo trascendencia y que determinó el resto de los procesos de composición fue la cuestión de los recursos hidráulicos: la condición de las tierras de regadío; los conflictos por las adjudicaciones de acequias y jagüeyes para beneficio de particulares en detrimento del bien público; y el dominio de la Corona a los remanentes de los ríos que estaban siendo enajenados por los regantes con mayores recursos económicos. El fiscal 
Manrique se refirió a la composición que efectuó el labrador Marcos Pérez en Izúcar, por medio de la cual adquirió el remanente del Nexapa (en la parte que llamaban Atoyaque) al precio de 10.000 pesos:

aún asentado el poderse la condición de que han de usar libremente de la composición y repartimiento de las aguas llevándolas de unas tierras a otras haciendo zanjas o como mejor les estuviere, se ha de entender sin perjuicio de unos y de otros o con su consentimiento, pues de otra manera no se debe dar; y en las otras de que no se ha de hacer novedad en los jagüeyes y que si quisieren a hacer otros los interesados puedan y no se le haya de impedir en contra ordenanzas y del bien público y uso general de las aguas, pues el encarcelarlas en los jagüeyes es prohibido y dañoso de unos para otros. Y esta condición, con la admisión del margen rubricada de vuestra excelencia y calidad de ella, son encontradas y las juzgo imposibles de conciliar, pues ejecutándose la condición y encarcelada el agua en los jagüeyes no queda remanente de que se pueda aprovechar su majestad, cuyo derecho se reserva para poderlas vender, como en el pleito de las aguas de Izúcar se acaba de ver probado por Marcos Pérez que compró a su majestad en diez mil pesos el remanente de todo el río de Atoyaque sin que se encarcelase por no poderle haber de otra manera (AGN, Tierras, vol. 3519, exp. 9, ff. 6v-7; Camacho, 2010: 303).

El decreto del licenciado Luis de Berrio y Montalvo atendió las consideraciones planteadas por el fiscal Francisco Manrique de Lara en las composiciones de Atlixco. Al alcalde Berrio y Montalvo le pareció que la resolución tomada por el fiscal para efectuar las composiciones colectivas era el mecanismo "más y seguro y útil al servicio de su majestad y menos gravoso a sus vasallos de estas provincias". Así, los ofrecimientos de los propietarios interesados debían de ser aceptados por las autoridades virreinales siempre y cuando correspondieran al número de unidades productivas y la calidad de sus tierras, respetando el acuerdo de suspender las mediciones de los terrenos. Pero el asunto de las composiciones de aguas estaba pendiente por resolver, como quedó asentado en su decreto:

En cuanto al uso y propiedad de jagüeyes y aguas podrá vuestra excelencia mandar se use de ellos como hasta aquí por esta provincia en lo que no fuere contra ordenanza y en lo demás en cuanto al paso de las aguas no siendo en perjuicio de tercero, porque esta parte que tocare, a derecho de tercero no compone vuestra excelencia, sino tan solamente el de su majestad (AGN, Tierras, vol. 3519, exp. 9, f. 8v).

Conviene hacer notar que los oidores tuvieron que ser muy cautelosos y aceptar las negociaciones propuestas por los labradores, pues a las autoridades virreinales no les convenía entrar en conflicto con los principales productores de trigo. Por el contrario, tuvieron que flexibilizar sus posturas y buscar las vías para continuar garantizando la productividad de los cereales y el abasto a las ciudades. Una forma de hacerlo fue confirmarles el derecho al agua.

Finalmente, en la Junta de la Real Hacienda realizada el 30 de mayo de 1643 , el virrey conde de Salvatierra y los demás oidores acordaron que el decre- 
to del licenciado Luis de Berrio y Montalvo -es decir, el procedimiento de composición colectiva ejecutado en Atlixco y Huejotzingo- debía guardarse, cumplirse y tener como resolución general para las que debieran hacerse en otras provincias por las razones arriba señaladas (AGN, Tierras, vol. 3519, exp. 9, f. 9). En consecuencia, las acequias, jagüeyes, presas y otras obras de conducción y captación hidráulica comenzaron a ser integradas a los títulos de composiciones, pero no de manera independiente, sino formando parte de las tierras, ingenios, trapiches o molinos. Lo anterior quedó reflejado en la ansiedad de los vecinos de la Villa de Carrión por acelerar la composición de las aguas junto a sus propiedades, en el momento que otorgaron nueve cartas poder y dos escrituras de obligación de pagos por las acequias de Cuilulco y Tlaxco (AGNEP, Atlixco, caja 32: 1640-1645, leg. 3, ff. 54-54v, 56-58v, 58v-59v, 61-62, 86v-88v, 102-103, $176 \mathrm{v}-177 \mathrm{v}, 190-191,192 \mathrm{v}-193 \mathrm{v}, 196-197 \mathrm{v}, 223 \mathrm{v}-225)$.

\section{CONFLICTOS DERIVADOS DE LAS COMPOSICIONES DE LAS AGUAS}

Naturalmente, el proceso de composiciones colectivas que admitió la adjudicación de acequias, presas y jagüeyes de manera particular a los labradores beneficiados, redundó en la afectación a los pueblos de indios y otros regantes. El 10 de abril de 1643, los naturales del pueblo de Izúcar denunciaron el agravio que recibían de los hacendados, que sabiéndose aventajados por los despachos de composiciones que recibirían, habían atajado el río Atoyaque -Nexapa en su corriente río abajo- en jagüeyes y presas. Los indios solicitaron la intervención de la autoridad local y apelaron a sus derechos desde tiempo inmemorial pues, a pesar de haberse efectuado repartimientos de agua en años anteriores, de nada habían servido las confirmaciones y amparos de los virreyes. Los indígenas tenían muy claro que eran los poseedores originales de las aguas, pero a raíz de las composiciones expusieron el incumplimiento de los repartimientos por parte de los labradores e incluso de otros pueblos, generando cada vez más réplicas, contradicciones y litigios. Las diligencias practicadas por el alcalde mayor Andrés Fernández de Córdoba corroboraron el estado en que estaba el río por causa de las presas de los hacendados:

llegué a una puertecilla de una acequia que es de los naturales de este pueblo y es la que pasa por la puerta del convento del Señor Santo Domingo, de él en la dicha puerta y acequia está a la orilla de la margen del río que viene del valle de Atrisco a este dicho pueblo y pasa por él en cuya madre principal y en la dicha acequia a la presente hora, que lo son las cinco de la tarde poco más o menos, no parece llevar dicho río y acequia ni correr por él ni por ella dos surcos de agua, porque es muy mínima y escasa y da la que por el dicho río y acequia corre $[. .$.$] que consta tener de agua el dicho pueblo y que la poca que entra en él es por$ 
mucha lama que por la esterilidad ha criado el dicho río de que necesariamente se podrá causar corrupción en la poco agua peste y enfermedad en las personas que forzosamente la han de beber por no haber otra (AHJP, exp. 1879. Izúcar, 1643, f. 10v).

Los hacendados, representados por don Juan Ibañes de Acoça (o Azoca), dueño de uno de los ingenios más grandes de la región, manifestaron una real provisión con fecha del 21 de noviembre de 1637, con la esperanza de que el alcalde mayor mantuviera sus presas. No obstante, éste reconoció tanto el derecho inmemorial de los indios como la preponderancia del bien público de las aguas, pues ordenó:

se rompan y abran todas las presas y tomas de agua que en el dicho río y parte de arriba hubiere en toda su jurisdicción pertenecientes a españoles y corra por su madre natural todo el día y noche de hoy sábado y el de mañana domingo y su noche, en cuyo término con el raudal de la dicha agua se limpiará la lama e inmundicia del dicho río, cuya ejecución su merced hará personalmente con el gobernador y cantidad de naturales que obligados de la necesidad claman este efecto (AHJP, exp. 1879. Izúcar, 1643, f. 11v).

Al concluir las composiciones en gran parte de las provincias novohispanas, ya se tenía una idea muy clara de los resultados. El 30 de junio de 1644 el conde de Salvatierra envió una carta al rey para informarle que la recaudación de este rubro hacendario había sido de medio millón de pesos en oro, los cuales llegarían a España en dos flotas. El virrey desdeñó las actividades de sus antecesores y exaltó sus propias acciones que hicieron posible la cobranza de las composiciones a los colonos sin agraviarlos demasiado (Carrera, 2018: Goyas, 2015: 69). Y así, los derechos del agua para tierras de riego, molinos, trapiches, batanes, ingenios y otras unidades productivas que generaran ganancias quedaron integrados en los títulos de composiciones despachados por este virrey, en razón de lo determinado por el alcalde de la Sala del Crimen y el fiscal de la Real Hacienda.

Con base en nuestra exploración cuantitativa de documentos concernientes a derechos de agua en el fondo Mercedes, hemos hecho un muestreo del periodo 1580-1660 en el que se manifiesta el mayor número de concesiones (Anexo 2). Como se exhibe en la tabla, la concentración de otorgamientos se dio entre los años 1611 a 1620, con total de 158 expedientes distribuidos de la siguiente manera: 142 "Mercedes de aguas" para españoles; seis para instituciones eclesiásticas -clero-; cuatro "Mercedes de agua" a pueblos de indios; cuatro "Composiciones de caballerías y aguas"; una "Composición de agua" a particulares; más un registro sin especificar. Pero donde debemos poner atención es en el periodo de 1641 a 1650, en el que se elevó a 22 el número de "Composiciones de tierras y aguas" a particulares, mientras que las "Composiciones de tierras y aguas 
generales o colectiva" a vecinos suman 25. Esta última categoría debe de entenderse como el resultado de las composiciones colectivas realizadas en las provincias del virreinato durante 1643. Por el momento estamos lejos de poder contabilizar a todos los beneficiarios con derechos a agua, ya sea por tierras de riego o para fuerza motriz. Lo que podemos advertir es que fueron cerca de 60 jurisdicciones cuyos vecinos recibieron despachos de composición colectiva entre 1643 y 1650 (Goyas, 2015: 65); es decir que el número de beneficiarios debe contarse por miles.

\section{COMENTARIOS FINALES}

La complejidad de la problemática histórica del agua no sólo radica en el manejo y control del recurso, sino también en las ideas que se tenían con respecto a este vital elemento de la naturaleza. Una forma de acercarse a estas ideas y de cómo éstas han cambiado a lo largo del tiempo es por medio del desarrollo y transformación de los derechos de propiedad, que no son otra cosa más que el reflejo de las dinámicas y relaciones sociales. El objetivo de este artículo ha sido analizar las distintas formas de uso y posesión del agua, revisar las reglamentaciones jurídicas que establecían los tipos de derechos y los mecanismos de concesión, para finalmente explicar de qué forma su carácter de bien público fue perdiendo preponderancia en el momento en que el dominio original de la Corona era trasladado para el aprovechamiento exclusivo de ciertos solicitantes. Este fenómeno apenas es perceptible dentro del marco de la política agraria impulsada por la monarquía para regularizar la propiedad rural desde finales del siglo XVI.

Las composiciones eran procedimientos que a los pueblos de indios no les correspondió acatar a lo largo del siglo XVII, debido a que sus bienes comunales entraban en el régimen de dominio útil y, por lo tanto, eran inalienables. Sin embargo, la suspensión de las diligencias de mensura durante las composiciones colectivas causó numerosos despojos y usurpaciones, no sólo a los naturales sino también para algunos pequeños propietarios. Además, las reformas a la política agraria no contemplaron el establecimiento de tribunales específicos para ventilar los desacuerdos, de modo que los inconformes tenían que dirigirse a las instancias locales para solicitar una resolución o, en su defecto, llevar sus quejas ante los oidores de la Real Audiencia. Despierta cierta curiosidad el hecho de no haber encontrado reclamaciones de los indígenas en contra de españoles en los años inmediatos a las composiciones colectivas de tierras. En otras palabras, 
los pleitos por tierras suscitados entre 1643 y 1650 refieren a otras causas y disputas por diversos recursos, pero no precisamente a las composiciones de tierras. Se ha ofrecido como posible explicación la profunda crisis demográfica por la que estaba atravesando la población indígena, cuyos sobrevivientes tuvieron pocas oportunidades de efectuar reclamaciones frente a los despojos.

No obstante, la demanda interpuesta por el común de naturales de Izúcar sobre sus derechos inmemoriales al afluente del río Nexapa demuestra que no fueron pasivos ante las composiciones de 1643, toda vez que pone de manifiesto su interés por la defensa de los recursos hídricos frente al procedimiento de enajenación para beneficio de los españoles. Este es un caso exitoso en el que los indígenas lograron conservar y ratificar sus derechos. A pesar de encontrarse en desventaja en medio de una política que privilegió los intereses económicos, la adjudicación de bienes públicos y la consolidación de la propiedad absoluta, supieron sacar provecho de las leyes y los códigos en la materia que colocaban al bien común y al derecho de los regantes sobre cualquier pretensión de apropiación particular del agua. 
ANEXO 1. NÚMERO DE EXPEDIENTES CONCERNIENTES A RECURSOS HÍDRICOS EN EL GRUPO DOCUMENTAL MERCEDES, AGNM (1542-1799)

\begin{tabular}{|c|c|c|c|c|c|c|c|}
\hline & $\begin{array}{r}1501- \\
1550 \\
\end{array}$ & $\begin{array}{r}1551- \\
1600 \\
\end{array}$ & $\begin{array}{r}1601- \\
1650 \\
\end{array}$ & $\begin{array}{r}1651- \\
1700 \\
\end{array}$ & $\begin{array}{r}1701- \\
1750 \\
\end{array}$ & $\begin{array}{r}1751- \\
1800 \\
\end{array}$ & Total \\
\hline \multicolumn{8}{|l|}{ CLERO } \\
\hline Amparo & & & 2 & 1 & 4 & 3 & 10 \\
\hline $\begin{array}{l}\text { Composición de tierras } \\
\text { y aguas }\end{array}$ & & & 2 & & & & 2 \\
\hline Contradicciones & & & 1 & & & & 1 \\
\hline Donaciones & & & & & & 1 & 1 \\
\hline Introducción de aguas & & & & & & 1 & 1 \\
\hline Mandamiento & & & 12 & 4 & 3 & & 19 \\
\hline Merced & 2 & 1 & 15 & 7 & 16 & 4 & 45 \\
\hline Venta & & & & & 1 & & 1 \\
\hline Total de expedientes: & 2 & $\mathbf{1}$ & 32 & 12 & 24 & 9 & 80 \\
\hline \multicolumn{8}{|l|}{ ESPAÑOL } \\
\hline Adjudicación de aguas & & & & & 1 & & 1 \\
\hline Amparo & & 1 & 2 & 4 & 1 & 2 & 10 \\
\hline Composición de aguas & & & 1 & 1 & 1 & & 3 \\
\hline $\begin{array}{l}\text { Composición de caballe- } \\
\text { rías y agua }\end{array}$ & & & 4 & & & & 4 \\
\hline $\begin{array}{l}\text { Composición de tierras } \\
\text { y aguas }\end{array}$ & & & 22 & & 1 & & 23 \\
\hline Concierto & & & 3 & & & & 3 \\
\hline Conducción de agua & & & & & & 2 & 2 \\
\hline Contradicciones & & & 1 & & 1 & 2 & 4 \\
\hline Donaciones & & & 1 & & & & 1 \\
\hline Mandamiento & 1 & & 4 & & 7 & 1 & 13 \\
\hline Merced & 2 & 54 & 192 & 91 & 65 & 31 & 435 \\
\hline Solares & & & 12 & & & & 12 \\
\hline Venta & & & & & & 1 & 1 \\
\hline Total de expedientes: & 3 & 55 & 242 & 96 & 77 & 39 & 512 \\
\hline
\end{tabular}




\begin{tabular}{|c|c|c|c|c|c|c|c|}
\hline & $\begin{array}{l}1501- \\
1550\end{array}$ & $\begin{array}{l}1551- \\
1600\end{array}$ & $\begin{array}{l}1601- \\
1650\end{array}$ & $\begin{array}{l}1651- \\
1700\end{array}$ & $\begin{array}{l}1701- \\
1750\end{array}$ & $\begin{array}{l}1751- \\
1800\end{array}$ & Total \\
\hline \multicolumn{8}{|l|}{$\begin{array}{l}\text { PUEBLO } \\
\text { DE INDIOS }\end{array}$} \\
\hline Amparo & & & 1 & 1 & & & 2 \\
\hline Arrendamiento & & & & & 3 & 1 & 4 \\
\hline Composición de aguas & & & & & 1 & & 1 \\
\hline Conducción de agua & & & & & 1 & & 1 \\
\hline Contradicciones & 1 & 3 & & & 1 & 2 & 7 \\
\hline Donaciones & & & & & 3 & 1 & 4 \\
\hline $\begin{array}{l}\text { Escritura sobre ciertas } \\
\text { aguas }\end{array}$ & & & & 1 & & & 1 \\
\hline Mandamiento & & & 7 & & & & 7 \\
\hline Merced & 3 & 5 & 4 & 2 & 2 & 4 & 20 \\
\hline Repartimiento & & & & 1 & & 1 & 2 \\
\hline Transacción sobre aguas & & & & 1 & & & 1 \\
\hline Total de expedientes: & 4 & 8 & 12 & 6 & 11 & 9 & 50 \\
\hline \multicolumn{8}{|l|}{ VECINOS } \\
\hline Composición de aguas & & & & & 1 & & 1 \\
\hline $\begin{array}{l}\text { Composición } \\
\text { de tierras y aguas }\end{array}$ & & & 25 & & & & 25 \\
\hline Conducción de agua & & & & 1 & 2 & 1 & 4 \\
\hline Contradicciones & & & & & & 2 & 2 \\
\hline Mandamiento & & & & & 1 & & 1 \\
\hline Merced & & & & & 5 & 3 & 8 \\
\hline Repartimiento & & & 1 & 1 & 2 & 1 & 5 \\
\hline Total de expedientes: & & & 26 & 2 & 11 & 7 & 46 \\
\hline \multicolumn{8}{|l|}{ SIN ESPECIFICAR } \\
\hline Conducción de agua & & & & 1 & 1 & & 2 \\
\hline Conexión de aguas & & & & & 2 & & 2 \\
\hline Contradicciones & & 1 & & & & & 1 \\
\hline Mandamiento & & 1 & & 1 & & & 2 \\
\hline Medida de aguas & & & & & 1 & & 1 \\
\hline Merced & & 2 & 2 & 3 & 7 & 1 & 15 \\
\hline Sin especificar & & & 1 & & & & 1 \\
\hline Venta & & & & & 1 & & 1 \\
\hline Total de expedientes: & & 4 & 3 & 5 & 12 & 1 & 25 \\
\hline TOTAL GENERAL & 9 & 68 & 315 & 121 & 135 & 65 & 713 \\
\hline
\end{tabular}


ANEXO 2. NÚMERO DE EXPEDIENTES CONCERNIENTES A COMPOSICIONES Y MERCEDES DE AGUA, PERIODO 1571-1660

\begin{tabular}{|c|c|c|c|c|c|c|c|c|c|c|}
\hline & $\begin{array}{c}1571- \\
1580 \\
\end{array}$ & $\begin{array}{c}1581- \\
1590 \\
\end{array}$ & $\begin{array}{l}1591- \\
1600 \\
\end{array}$ & $\begin{array}{c}1601- \\
1610 \\
\end{array}$ & $\begin{array}{c}1611- \\
1620 \\
\end{array}$ & $\begin{array}{c}1621- \\
1630 \\
\end{array}$ & $\begin{array}{c}1631- \\
1640 \\
\end{array}$ & $\begin{array}{c}1641- \\
1650 \\
\end{array}$ & $\begin{array}{c}1651- \\
1660 \\
\end{array}$ & $\begin{array}{c}\text { Total } \\
\text { general }\end{array}$ \\
\hline \multicolumn{11}{|l|}{ CLERO } \\
\hline $\begin{array}{l}\text { Composi- } \\
\text { ción de tie- } \\
\text { rras y aguas }\end{array}$ & & & & & & & & 2 & & 2 \\
\hline Merced & & & & 1 & 6 & 2 & 1 & 5 & 1 & 16 \\
\hline $\begin{array}{l}\text { Total de } \\
\text { concesiones: }\end{array}$ & & & & 1 & 6 & 2 & 1 & 7 & 1 & 18 \\
\hline \multicolumn{11}{|l|}{ ESPAÑOL } \\
\hline $\begin{array}{l}\text { Com- } \\
\text { posición de } \\
\text { aguas }\end{array}$ & & & & & 1 & & & & & 1 \\
\hline $\begin{array}{l}\text { Composi- } \\
\text { ción de caba- } \\
\text { llerías y agua }\end{array}$ & & & & & 4 & & & & & 4 \\
\hline $\begin{array}{l}\text { Composición } \\
\text { de tierras y } \\
\text { aguas }\end{array}$ & & & & & & & & 22 & & 22 \\
\hline Merced & 12 & 14 & 20 & 19 & 142 & 13 & 13 & 5 & 2 & 240 \\
\hline $\begin{array}{l}\text { Total de } \\
\text { concesiones: }\end{array}$ & 12 & 14 & 20 & 19 & 147 & 13 & 13 & 27 & 2 & 267 \\
\hline \multicolumn{11}{|l|}{$\begin{array}{l}\text { PUEBLO } \\
\text { DE INDIOS }\end{array}$} \\
\hline Merced & & & & & 4 & & & & & 4 \\
\hline $\begin{array}{l}\text { Total de } \\
\text { concesiones: }\end{array}$ & & & & & 4 & & & & & 4 \\
\hline \multicolumn{11}{|l|}{ VECINOS } \\
\hline $\begin{array}{l}\text { Composi- } \\
\text { ción de tie- } \\
\text { rras y aguas }\end{array}$ & & & & & & & & 25 & & 25 \\
\hline $\begin{array}{l}\text { Total de } \\
\text { concesiones: }\end{array}$ & & & & & & & & 25 & & 25 \\
\hline \multicolumn{11}{|l|}{$\begin{array}{l}\text { SIN ES- } \\
\text { PECIFICAR }\end{array}$} \\
\hline Merced & & & & & 1 & & & 1 & & 2 \\
\hline $\begin{array}{l}\text { Total de } \\
\text { concesiones: }\end{array}$ & & & & & 1 & & & 1 & & 2 \\
\hline $\begin{array}{l}\text { Total } \\
\text { general }\end{array}$ & 12 & 14 & 20 & 20 & 158 & 15 & 14 & 60 & 3 & 316 \\
\hline
\end{tabular}


IMAGEN 1. REPRESENTACIÓN DEL RÍO ATOYAC EN UNA SOLICITUD DE MERCED DE TIERRAS EN EL PUEBLO DE HUEJOTZINGO, 1582

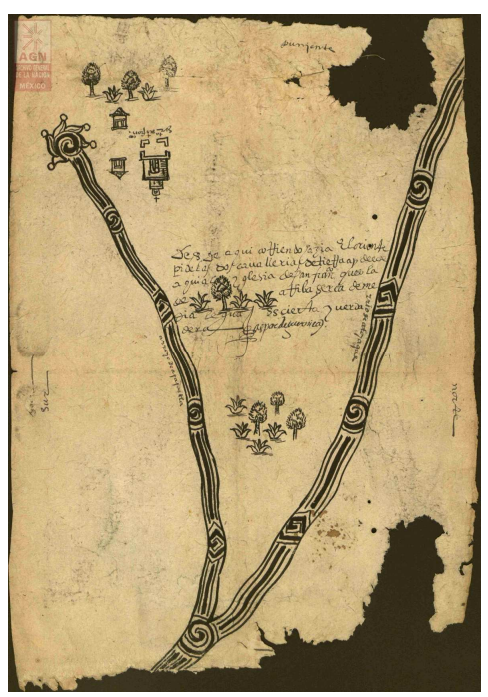

Fuente: "Huejotzingo. Diligencias sobre dos caballerías de tierra que Bernardo Rodríguez pide por merced en términos de esta jurisdicción en el pago nombrado Apapaxtla, 1582". AGN, Tierras, vol. 2708, exp. 6, f. 9. Plano en papel maguey. Número de catálogo 1757F.

IMAGEN 2. HuEJotZINGO Y SANTA ANA XAMIMILULCO, 1742

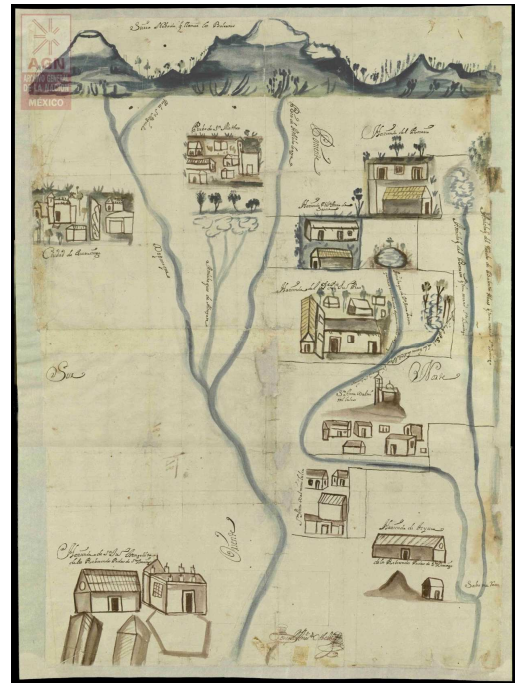

Fuente: "Huejotzingo. El convento de Santo Domingo, de Puebla, dueño de la hacienda de San Juan Evangelista Teyuca, contra María Sáenz de la Corte y Juan Pérez Fernández de Salgo, dueños de la hacienda de Santa Ana Xamimilulco, sobre propiedad de aguas, 1690-1743", AGN, Tierras, vol. $645,2^{\mathrm{a}}$. pte., exp. 2, f. 77. Número de catálogo 0807F. 
IMAGEN 3. "MAPA DE LA CIUDAD DE PUeBla DE LOS ÁNGeles Y DEL VALLE DE IZÚCAR ELABORADO POR DON NiCOLÁs ZAMUdiO POR ORDEN DEL SEÑOR VIRREY DE LA NUEVA ESPAÑa Y CON LA FINALIDAD DE REPRESENTAR FIELMENTE LA ZANJA DE AGUA DEL RíO ATOYAC", SIGLO XVIII

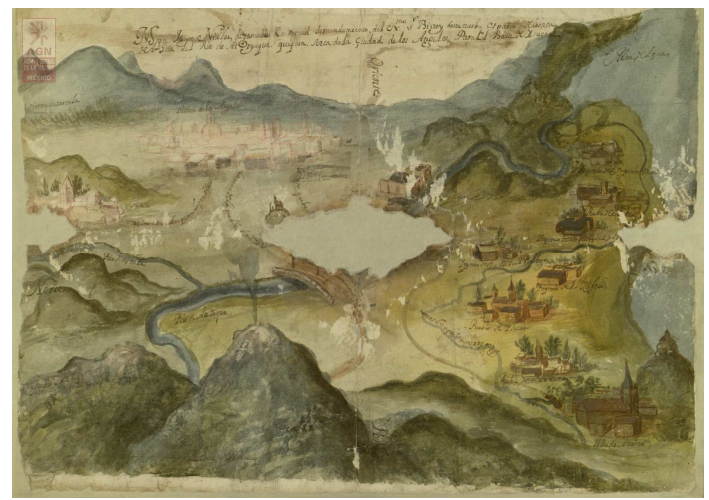

Fuente: AGN, Civil, vol. 1276, f. 120. Número de catálogo 4129.

\section{BIBLIOGRAFÍA}

Aboites, L. (2005). Breve revisión de la historiografía sobre la cuestión hidráulica del norte de México en el siglo XX. En G. Miño, É. Hurtado (eds.), Los usos del agua en el centro y norte de México: historiografía, tecnología y conflictos (pp. 15-36). Zacatecas, México: Universidad Autónoma de Zacatecas, El Colegio de México.

Camacho, G. (1998). Repartimientos y conflictos por agua en los valles de Atlixco e Izúcar (15501650) [Tesis de maestría]. Ciudad de México, México: CIESAS.

Camacho, G. (2010). La competencia por el agua en el Valle de Izúcar, Puebla. Los repartimientos de agua y los ingenios, 1550-1650. Fronteras de la historia, 15(2), pp. 282-307.

Carrera, S. E. (2018). Sementeras de papel. La regularización de la propiedad rural en la Huasteca serrana, 1550-1720. Ciudad de México, México: El Colegio de México, CIESAS.

Castañeda, R. (2005). Las aguas de Atlixco: estado, haciendas, fábricas y pueblos, 1880-1920. Ciudad de México, México: CIESAS, Archivo Histórico del Agua, Comisión Nacional del Agua, El Colegio de México.

Fernández, I., Endfield, G., O'Hara, S. (2004). Estrategias para el control del agua en Oaxaca colonial. Estudios de Historia Novohispana, (31), pp. 137-198.

Garavaglia, J. C. (1996). Atlixco: el agua, los hombres y la tierra en un valle mexicano (siglos XIV-XVII). En Tortolero, A. (ed.), Tierra, agua y bosques: historia y medio ambiente en el México central (pp. 69-125). Ciudad de México, México: CEMCA, Instituto de Investigaciones Dr. José María Luis Mora, Universidad de Guadalajara, Potrerillos Editores A. C.

Gómez, J. (2005). La lucha por el control del agua en la Villa de Aguascalientes durante los siglos XVII y XVIII. En G. Miño, É. Hurtado (eds.), Los usos del agua en el centro y norte de México: historiografía, tecnología y conflictos (pp. 37-81). Zacatecas, México: Universidad Autónoma de Zacatecas, El Colegio de México. 
Goyas, R. (2015). Las Composiciones de Tierras de 1643 en la Nueva España. Revista de Historia Iberoamericana, 8(2), pp. 54-75.

Jiménez, J. R. (2003). Composición de tierras de los vecinos de Querétaro con Su Majestad. Querétaro, México: Universidad Autónoma de Querétaro.

Lanz, J. T. (1982). Legislación de aguas en México. Villahermosa, México: Consejo Editorial del Estado de Tabasco.

León Pinelo, A. (1992 [1680]). Recopilación de las Indias [vol. 3]. Ciudad de México: Porrúa.

Lipsett-Rivera, S. (1992). Indigenous Communities and Water Rights in Colonial Puebla: Patterns of Resistance. The Americas, 48(4), pp. 463-483.

Lipsett-Rivera, S. (1993). Water and Bureaucracy in Colonial Puebla de Los Angeles. Journal of Latin American Studies, 25(1), pp. 25-44.

Lipsett-Rivera, S. (1999). To Defend Our Water with the Blood of Our Veins: The Struggle for Resources in Colonial Puebla. Albuquerque: The University of New Mexico Press.

Loreto, R. (1994). De aguas dulces y aguas amargas o de cómo se distribuía el agua en la ciudad de Puebla durante los siglos XVIII y XIX. En R. Loreto, F. Cervantes (eds.), Limpiar y obedecer. La basura, el agua y la muerte en la Puebla de los Ángeles. 1650-1925 (pp. 127-186). Puebla, México: BUAP, CEMCA, Colegio de Puebla A. C.

Loreto, R. (2009a). Introducción. Agua, poder urbano y metabolismo social (pp. 9-24). Puebla, México: BUAP.

Loreto, R. (2009b). Agua, acequias, heridos y molinos. Un ejemplo de dinámica ambiental urbana. Puebla de los Ángeles, siglos XVI-XIX. En R. Loreto (ed.), Agua, poder urbano y metabolismo social (pp. 47-76). Puebla, México: BUAP.

Macías, J. L. (2005). Geología e historia eruptiva de algunos de los grandes volcanes activos de México. Boletín de la Sociedad Geológica Mexicana, 57(3), pp. 379-424.

Margadant, G. (1989). El agua a la luz del derecho novohispano. Triunfo del realismo y flexibilidad. Anuario Mexicano de Historia del Derecho, (1), pp. 113-146.

Margadant, G. (1992). Las aguas del subsuelo en el derecho indiano. Realidad histórica versus dogma abstracto en la estructura general del derecho indiano. El problema de la vigencia de normas surgidas de errores científicos. Anuario Mexicano de Historia del Derecho, (4), pp. 239-258.

Meyer, M. (1997). El agua en el suroeste hispánico: una historia social y legal 1550-1850. Ciudad de México, México: CIESAS, Instituto Mexicano de Tecnología del Agua.

Ots Capdequí, J. M. (1989). El Estado español en las Indias. Ciudad de México, México: FCE.

Palerm Viqueira, J., Chairez Araiza, C. (2002). Medidas antiguas de agua. Relaciones. Estudios de historia y sociedad, (92), pp. 227-251.

Paredes, C. S. (1991). La región de Atlixco, Huaquechula y Tochimilco. La sociedad y la agricultura en el siglo XVI. Puebla, México: CIESAS, FCE, Gobierno del Estado de Puebla. 
Peset, M., Menegus, M. (1994). Rey soberano o rey propietario. Historia Mexicana, 43(4), pp. 563598.

Prem, H. (1988). Milpa y hacienda. Tenencia de la tierra indígena y española en la cuenca del Alto Atoyac, Puebla, México (1520-1650). Puebla: CIESAS, FCE, Gobierno del Estado de Puebla.

Rojas, T. (2009). Las obras hidráulicas en las épocas prehispánicas y colonial. En Semblanza histórica del agua en México (pp. 9-25). Ciudad de México, México: SEMARNAT.

Salazar, C. (2000). Uso y distribución del agua en el valle de Tehuacán. El caso de San Juan Bautista Axalpan, Pue. (1610-1798). Ciudad de México, México: CONACULTA, INAH.

Solano, F. de (1984). Cedulario de Tierras. Compilación de legislación agraria colonial (14971820). Ciudad de México, México: UNAM.

Torales, M. C. (2005). Tierras de indios, tierras de españoles. Confirmación y composición de tierras y aguas en la jurisdicción de Cholula (siglos XVI-XVIII). Ciudad de México, México: Universidad Iberoamericana.

Taylor, W. (1975). Land and Water Rights in the Viceroyalty of New Spain. New Mexico Historical Review, 50(3), pp. 189-212.

Zavala, S. (1994). El servicio personal de los indios en la Nueva España (1636-1699) [Tomo VI]. Ciudad de México, México: El Colegio de México, El Colegio Nacional.

\section{Archivos consultados}

AGI: Archivo General de Indias, Sevilla, España.

AGN: Archivo General de la Nación, México.

AGNEP: Archivo General de Notarías del Estado de Puebla.

AHJP: Archivo Histórico Judicial del Estado de Puebla, Centro Regional INAH-Puebla.

BNM: Biblioteca Nacional de México, Universidad Nacional Autónoma de México.

\section{Breve CV del autor}

Sergio Eduardo CARRERa QueZADA, Doctor en historia por la Universidad Nacional Autónoma de México, maestro en antropología social por la Universidade Federal de Santa Catarina, Brasil y licenciado en etnohistoria por la Escuela Nacional de Antropología e Historia. Es profesor investigador del Centro de Estudios Históricos de El Colegio de México. Fue investigador huésped y docente en el Centro de Investigaciones y Estudios Superiores en Antropología Social, Unidad Peninsular. Su tesis doctoral obtuvo el XV Premio Banamex Atanasio G. Saravia de Historia Regional Mexicana 2012-2013 y el premio Francisco Javier Clavijero 2014, que otorga el Instituto Nacional de Antropología e Historia (INAH).

Es autor de Sementeras de papel: la regularización de la propiedad agraria en la Huasteca serrana, 1550-1720 (2018), Las voces de la fe. Las cofradías en México (siglos XVII-XIX) (2011) y A son de campana. La fragua de Xochiatipan (2007).

Sus líneas de investigación son la historia agraria y la regularización de la propiedad rural durante el periodo colonial, así como la organización espacial y política de los pueblos y sociedades indígenas.

Actualmente investiga temas sobre la historia ambiental y análisis del paisaje en México. 


\section{Short biography}

Sergio Eduardo CARRERA QuEZADA - Professor and researcher at the Centro de Estudios Históricos, El Colegio de México. He was guest researcher and teacher at the Centro de Investigaciones y Estudios Superiores en Antropología Social, Unidad Peninsular. His doctoral thesis received the XV Atanasio G. Saravia Prize for Mexican Regional History 2012-2013 and the 2014 Francisco Javier Clavijero Prize from the Instituto Nacional de Antropología e Historia (INAH).

$\mathrm{He}$ is the autor of Sementeras de papel: la regularización de la propiedad agraria en la Huasteca serrana, 1550-1720 (2018), Las voces de la fe. Las cofradías en México (siglos XVII-XIX) (2011) and A son de campana. La fragua de Xochiatipan (2007).

His main scholarly interest is in the agrarian history and the regularization of rural property in New Spain. His current research is in environmental history and landscape analysis in Mexico. 